\title{
O Cristo Vivo na Civilização: Protestantismo e Espaço Público no Brasil (1930-1932) ${ }^{1}$
}

\author{
The Living Christ in the Civilization: \\ Protestantism and Public Space in Brazil (1930-1932).
}

Lyndon de Araújo Santos*

\begin{abstract}
Resumo
Este artigo analisa o relatório oficial produzido pela 11a. Convenção Mundial das Escolas Dominicais na cidade do Rio de Janeiro, no ano de 1932. O relatório traduz o universo protestante (europeu e norteamericano, latino-americano e brasileiro) do início da década de 1930, os seus discursos, as suas práticas e suas visões de mundo. Os sentidos atribuídos pelos protestantes para a ação política, a educação e a civilização são compreendidos a partir do contexto entre guerras, da crise do imperialismo europeu e da eclosão de uma guerra civil no Brasil. A realização desta convenção no Rio de Janeiro representou uma demonstração de força política dos protestantes brasileiros junto ao governo provisório de Getúlio Vargas, que havia chegado ao poder pela Revolução de 1930, reaproximando a Igreja Católica e estabelecendo outros rumos para a sociedade. Trata-se, portanto, da análise histórica de um documento a partir de um recorte temporal atravessado por múltiplas forças que reordenaram a presença protestante no espaço público, na política, na cultura, enfim, no campo religioso brasileiro.
\end{abstract}

Palavras-chave: Protestantismo, Civilização, Espaço Público, Campo Religioso, História.

\begin{abstract}
This article analyses the official report produced by the 11th World Convention of Sunday Schools that took place in Rio de Janeiro in 1932. The report reveals the protestant world (European, North American, Latin American and Brazilian) in the beginning of the 1930's, its speeches, its practices and its views of the world. The senses and meanings that protestants gave to political actions, to education and to civilization can be understood from the context that included a period between wars, the crises of the European imperialism and a civil war in Brazil. The Convention held in Rio de Janeiro represented a demonstration of political strength Brazilian protestants had in the provisional government of Getúlio Vargas, who became the president through the Revolution of 1930, getting closer to the Catholic Church and establishing other routes for the society. Therefore, this article is a historical analysis of a document, in a period of time, influenced by multiple forces and which opened new ways for the protestant presence in the public space, in politics, in the culture, and in the Brazilian religious field.
\end{abstract}

Key words: Protestantism, Civilization, Public Space, Religious Field, History.

\footnotetext{
Artigo submetido em 21 de janeiro de 2017 e aprovado em 08 de setembro de 2017.

${ }^{1}$ Texto originalmente apresentado no XIII Congresso Latinoamericano sobre Religión y Etnicidad: Diálogo, Ruptura y Mediación en contextos religiosos (Simpósio XVI - Religión y Política), promovido por ALER - ASSOCIACIÓN LATINOAMERICANA PARA EL ESTUDIO DE LAS RELIGIONES LATINO AMERICANAS e Universidad de Granada, Espanha (13 a 17/07/2010). A participação no Congresso contou com o apoio da FAPEMA - Fundação de Amparo à Pesquisa e ao Desenvolvimento Científico-Tecnológico do Maranhão. $O$ artigo foi atualizado e ampliado visando a sua publicação.

" Doutor em História (UNESP, 2005) e pós-doutorado (UFF, 2014), professor do Departamento de História (UFMA) e pesquisador nos PPGs em História e em Ciências Sociais (UFMA). Coordena o GP Religião, História e Cultura Material. País de Origem: Brasil. E-mails: lyndonasantos@gmail.com/lyndon.santos@ufma.br
}

Horizonte, Belo Horizonte, v. 15, n. 47, p. 949-973, jul./set. 2017 - ISSN 2175-5841 


\section{Introdução}

Protestantes ou evangélicos no Brasil e na América Latina têm se afirmado atualmente como força política e religiosa por meio de uma intensa presença no espaço público, sob variadas formas, discursos e estratégias. ${ }^{2}$ Isto representa um conjunto de manifestações que se projetam para além do campo religioso, afirmando-se no cotidiano das relações sociais e nos âmbitos cultural, político e midiático.

A presença da religião no espaço público tem sido temática discutida no campo das ciências sociais, das ciências da religião e da história (BIRMAN, 2003; HERVIEU-LÉGER, 2008; GIUMBELLI, 2008; MONTERO, 2009). O advento da modernidade com a laicização do estado e o deslocamento da religião como matriz de sentido para um espaço não central, tem se constituído um eixo de compreensão da presença da religião nesse novo ordenamento das sociedades ocidentais. Tratase, sobretudo de um processo histórico constituído de singularidades sociais e percursos institucionais a serem compreendidos.

Neste reordenamento, a religião passou a comportar-se pela necessidade de atuar no espaço público demarcando sua visibilidade, seu discurso, suas estratégias e suas práticas. A religião com suas instituições, crenças e valores, passou a se representar na política e na cultura, agora como esferas laicizadas. O surgimento de uma sociedade plural com suas manifestações ideológicas, culturais e religiosas, levou a religião a se adaptar a um cenário mais complexo e dinâmico, a fim de garantir sua sobrevivência por meio da tradição, da memória, dos seus rituais e de suas representações sociais. As instituições religiosas constroem seus próprios discursos e visibilidade social, em disputas pelas posições e hegemonias nos campos religioso, cultural e político (BOURDIEU, 2009, p. 69).

\footnotetext{
${ }^{2}$ Utilizamos intencionalmente as expressões protestantes e evangélicos como sinônimas, pelo fato de que, no contexto histórico da década de 1930, não havia ainda as diferenciações que adquiriram em termos de práticas e de concepções teológicas e litúrgicas, após a Segunda Guerra Mundial até os nossos dias.
} 
A partir deste aporte teórico e do contexto histórico, o presente artigo procura compreender historicamente um contexto singular no percurso do protestantismo, tanto mundial como latino-americano e brasileiro, que foi a realização da $11^{a}$. Convenção Mundial das Escolas Dominicais, na cidade do Rio de Janeiro, então Distrito Federal, em 1932, a primeira realizada na América do Sul. Sua importância e relevância estão no fato de ter acontecido num contexto de intensas mudanças e transformações, tanto no cenário externo como no interno.

A Europa vivia a tensão e a iminência de um segundo conflito bélico, após a crise econômica de 1929 que afetou a economia capitalista e o liberalismo. O Brasil vivia o ambiente pós revolução quando grupos oligárquicos destituíram o presidente eleito Washington Luís e assumiram o governo provisório em 1930, levando o país a uma guerra civil iniciada em julho de 1932. Não somente pela confluência destes acontecimentos, a interpretação histórica da realização desta convenção auxilia a discussão acerca do reordenamento da religião diante das mudanças políticas e culturais em curso.

O protestantismo pautava sua ação religiosa com base nos discursos sobre a educação, a civilização e o valor do indivíduo.3 Estes enunciados foram centrais para os protestantes desde a passagem dos séculos XIX-XX. No entanto, estas plataformas discursivas se encontravam numa fronteira de esgotamento de sentido diante do desmoronamento de valores e ideais outrora acreditados pelo ocidente.

Nosso interesse nesta discussão está na percepção do comportamento social dos protestantes quando da recomposição dos campos político, cultural e religioso, numa conjuntura de rápidas transformações (BOURDIEU, 2009, p. 72).4 Em outras palavras, situamos como se deu a reinserção da presença evangélica no

\footnotetext{
${ }^{3}$ Quando nos referimos ao protestantismo como força religiosa e cultural queremos dizer um conjunto de agentes que formavam uma dada unidade discursiva comum: sociedades bíblicas, congressos, editoras, denominações, institutos teológicos, universidades, igrejas, denominações, associações, instituições filantrópicas.

${ }^{4} \mathrm{O}$ recorte histórico aqui apresentado pretende pontuar como estas relações se deram numa conjuntura especialmente marcada por profundas mudanças em seu ritmo e em seus significados.
} 
espaço público numa dada conjuntura histórica e seus desdobramentos encontrados em nossos dias, sobretudo no Brasil.

\section{As Convenções da Associação Mundial das Escolas Dominicais}

As convenções mundiais das Escolas Dominicais eram eventos que ocorriam desde o ano de 1889, organizadas pela Associação Mundial de Escolas Dominicais.5 Em fins do século XVIII, um jornalista inglês chamado Robert Raykes, preocupado com o destino das crianças e adolescentes nas ruas sem cuidado, instrução e levados à delinquência, iniciou um movimento em prol da educação popular a partir das igrejas (ALMEIDA, 2015, p. 106). O movimento logo se espalhou rapidamente pela Inglaterra e pela Europa protestante, numa mobilização assistencialista e educacional ao mesmo tempo, formando uma das práticas mais enraizadas nas igrejas protestantes até os nossos dias, as escolas dominicais.

As escolas dominicais se tornaram prática central por parte das igrejas protestantes. No Brasil, a primeira escola dominical regular iniciou no ano de 1855 , com a missionária inglesa Sarah Poulton Kalley, em Petrópolis (ROCHA, 2013, p. 33). Em 1921, Francisco de Souza, pastor da Igreja Evangélica Fluminense, Rio de Janeiro, publicou na Revista de Cultura Religiosa, o seguinte depoimento:

A história do protestantismo dos últimos tempos é, por assim dizer, a história da Escola Dominical. É ela que está concorrendo de modo relevante para que o protestantismo realize a sua principal aspiração: pôr a Bíblia aberta nas mãos e no coração dos povos. É ela, já o asseveravam, "o viveiro da igreja". É por esse poderoso instrumento que a igreja de Nosso Senhor Jesus Cristo vai libertando as massas do ateísmo, da incredulidade prática, da idolatria, crendices e superstição. O seu misterioso poder está no estudo sistemático da Escritura Santa, na sua organização e na possibilidade de moldar-se a métodos estritamente científicos. É um campo de ação que toca as raias do infinito. E, assim

\footnotetext{
5 "Os fins e os objetivos desta organização são de ordem espiritual, educacional, missionária e beneficente, sendo seu propósito particular promover a educação cristã, incluindo a obra organizada das Escolas Dominicais, encorajar o estudo da Bíblia e cooperar na propagação da religião cristã e no desenvolvimento do caráter cristão, em todo o mundo". Estatuto da Associação Mundial de Escolas Dominicais (MOREIRA, 1932, p. 283).
} 
sendo, é correta a afirmação de que três quartos das conversões ao Evangelho provem das suas aulas (Citado por ALMEIDA, 2015, p. 107).

Havia a convicção quanto a eficácia do método de ensino e de transmissão da fé por meio da escola dominical, cujo objetivo principal era disponibilizar a Bíblia como livro sagrado e libertar seus leitores das trevas da ignorância religiosa e cultural. Souza expressava a concepção alimentada no protestantismo brasileiro da educação como instrumento tanto de instrução como de conversão. O lema disseminado pelos protestantes até meados do século XX era "em cada igreja, uma escola", referindo-se tanto ao ensino religioso dominical como o formal de conteúdo secular com escolas diárias.

De acordo com a própria percepção histórica da Associação Mundial, três fases poderiam ser traçadas em sua trajetória. As primeiras convenções eram voltadas para "confraternização, inspiração e edificação", mas, a partir de 1907, em Roma, numa segunda fase tornou-se uma estrutura permanente. Em 1924, na cidade de Glasgow, Escócia, assumiu por fim a estrutura de "uma federação mundial de organizações nacionais e internacionais interessadas na educação religiosa cristã" (MOREIRA, 1932, p. 63). ${ }^{6}$

As convenções tinham o poder de captação de recursos e de reunir instituições de ensino, igrejas, lideranças eclesiásticas, pedagogos e intelectuais do mundo protestante que discutiam e definiam as formas de atuação da educação religiosa. A regularidade das convenções mostrava a capacidade de organização dos protestantes, a destinação de recursos e a representatividade de diferentes continentes onde o protestantismo estava presente com suas ações missionárias, educacionais e assistencialistas. A julgar procedente e próxima ao real, a projeção do número das pessoas alcançadas por meio das escolas dominicais era de mais de 30 milhões em todos os continentes (FARIS, 1928, p. 381).

${ }^{6}$ Nesta convenção, 12 representantes do Brasil estavam presentes (FARIS, 1924, p. 367-370). 
Na sua maioria, as convenções ocorreram na Europa e nos Estados Unidos, numa relação evidente da força do protestantismo anglo-saxão, equivalente à presença do imperialismo dos países do hemisfério norte. Além das cidades de Tóquio e de Jerusalém, o Rio de Janeiro foi uma exceção, sobretudo porque se tratava de uma cidade situada na América Latina. O quadro abaixo traz a sequência regular dos congressos mundiais com as suas representações de delegados, demonstrando a força desse movimento agregador de recursos e mobilizador de capital humano, organicamente expressivo no cenário maior do protestantismo mundial.

\section{Quadro o1 - Convenções Mundiais de Escolas Dominicais7}

\begin{tabular}{|c|c|c|c|}
\hline Local & Data & Delegados & Representações \\
\hline I - Londres, Inglaterra & $\begin{array}{c}01 \mathrm{a} \\
06 / 07 / 1889\end{array}$ & 904 & $\begin{array}{c}\text { EUA (360), Canadá (69), Grã- } \\
\text { Bretanha e Irlanda (440), } \\
\text { Outros países (35). }\end{array}$ \\
\hline II - St. Louis, EUA & $\begin{array}{c}30 / 08 \mathrm{a} \\
05 / 09 / 1893\end{array}$ & 882 & $\begin{array}{l}\text { Grã-Bretanha (55), Alemanha, } \\
\text { Índia, Suécia, Burma. }\end{array}$ \\
\hline III - Londres, Inglaterra & $\begin{array}{c}11 \mathrm{a} \\
16 / 07 / 1898\end{array}$ & 1154 & $\begin{array}{c}\text { EUA (299), Grã-Bretanha, } \\
\text { Áustria, Bélgica, Alemanha, } \\
\text { Holanda, Noruega, Suécia, Suíça. }\end{array}$ \\
\hline IV - Jerusalém, Israel & $\begin{array}{c}17 \mathrm{a} \\
19 / 04 / 1904 \\
\end{array}$ & 1526 & 25 países \\
\hline V - Roma, Itália & $\begin{array}{c}18 \mathrm{a} \\
23 / 05 / 1907 \\
\end{array}$ & 1118 & 66 países \\
\hline VI - Washington, EUA & $\begin{array}{c}19 \mathrm{a} \\
24 / 05 / 1910 \\
\end{array}$ & 2500 & - \\
\hline VII - Zurique, Suíça & o8 a $15 / 1913$ & 2609 & 51 países \\
\hline VIII - Tóquio, Japão & $\begin{array}{c}05 \mathrm{a} \\
14 / 10 / 1920 \\
\end{array}$ & 1814 & 5 continentes e 17 países \\
\hline IX - Glasgow, Escócia & $\begin{array}{c}18 \mathrm{a} \\
26 / 06 / 1924\end{array}$ & 2810 & 54 países \\
\hline X - Los Angeles, EUA & $\begin{array}{c}11 \mathrm{a} \\
18 / 07 / 1928 \\
\end{array}$ & 7631 & 51 países \\
\hline XI - Rio de Janeiro, Brasil & $\begin{array}{c}25 \mathrm{a} \\
31 / 07 / 1932\end{array}$ & 1316 & 33 países \\
\hline
\end{tabular}

Fonte: MOREIRA, 1932, p. 16-22. (Quadro elaborado pelo autor).

\footnotetext{
${ }^{7}$ Em 1917 não houve convenção por conta da primeira guerra e em 1936 foi realizada provavelmente a última em Oslo, Noruega, com nova interrupção pela segunda guerra.
} 
As razões para a escolha do Brasil como sede da convenção podem ser encontradas na representatividade da delegação brasileira nas últimas convenções (1913, 1924 e 1928), na sua importância estratégica na América Latina e no deslocamento das relações de força do protestantismo europeu para o continente norte-americano, sob a liderança dos Estados Unidos. O Brasil representava uma das mais promissoras regiões de crescimento evangélico no mundo, processo que aconteceria de forma acentuada somente a partir da década de 1980 em diante.

Junto com estes fatores, a mobilização dos protestantes na América Latina foi decisiva desde 1910. Neste ano, na cidade de Edimburgo na Escócia, ocorreu a Conferência Mundial de Missões com a presença de brasileiros e latino-americanos que discordaram da perspectiva do congresso de que a América Latina já era um continente cristão, sem haver a necessidade de ser evangelizada. Foi um evento de significativa importância pois reconfigurou o protestantismo ocidental em termos de interpretação do mundo e das estratégias da ação missionária, aprofundando a visão ecumênica por um lado, e por outro, o deslocamento do poder norteamericano em relação à Europa quanto aos rumos do protestantismo mundial.

Segundo os participantes brasileiros e latino-americanos, o diagnóstico estava equivocado na sua dimensão ontológica e missionária. Como desdobramento dessa reação e sob a liderança norte-americana, em 1916, o Congresso do Panamá estabeleceu linhas de ação religiosa e cultural para a América Latina, partindo do pressuposto de que o continente não era cristão, na perspectiva protestante, e que necessitava de uma ação conjunta mais efetiva na sua evangelização.

Apesar de ser escolhido como sede do evento, o Brasil contava com um contingente protestante muito pequeno em relação à totalidade da população. Entretanto, apresentava-se e se encontrava, de certa forma, bem estruturado e organizado, por meio de igrejas, denominações, escolas, hospitais, sociedades bíblicas, associações e imprensa própria, representando um potencial crescimento futuro. Numa projeção otimista, Galdino Moreira disse haver 
atualmente uma comunidade evangélica total, no Brasil, computando mais de 400.000 membros, dos quais pelo menos 200.000 são crianças de idade escolar. Provavelmente, não há dessas mais que 10.000 crianças na escola primária e 10.000 nas escolas secundárias, da igreja evangélica ... (MOREIRA, 1932, p. 233).

Os protestantes depois de um século presentes no Brasil, atuavam em todo o território nacional por meio de suas instituições, igrejas e ações missionárias proselitistas. A reconstrução social rumo à civilização no continente passaria pela regeneração do indivíduo, tendo a educação, a alfabetização e a distribuição de Bíblias como meios para a sua evangelização.

\section{Análise do Relatório}

O relatório da convenção pode ser considerado como um dos mais importantes e significativos documentos produzidos pelos protestantes na primeira metade do século XX. ${ }^{8}$ Isto pelo fato de ser o registro da mentalidade de uma geração de elites evangélicas organizadas em torno do movimento histórico das Escolas Dominicais, articuladas num projeto de construção de uma sociedade moldada pelos valores cristãos. Os temores em relação à situação de guerra civil interna limitaram a vinda de delegados de outros países, fator aliado às dificuldades financeiras causadas pela crise de 1929.

Nossa fonte compõe-se de artigos, relatórios, dados estatísticos e históricos, e experiências vivenciadas pelos 1316 delegados registrados, num total de 1849 participantes oriundos de várias partes do mundo.

\footnotetext{
${ }^{8}$ Relatório também publicado em inglês nos Estados Unidos com o título The living Christ in the world Fellowship of religious Education.
} 
Quadro 02 - Estatísticas dos Participantes

\begin{tabular}{|c|c|}
\hline Delegados & Números \\
\hline Brasileiros & 1.038 \\
\hline Sul-americanos & 58 \\
\hline Demais países & 220 \\
\hline TOTAL DE DELEGADOS REGISTRADOS & $\mathbf{1 3 1 6}$ \\
\hline Membros do coro & 312 \\
\hline Representação alegórica & 221 \\
\hline TOTAL DE INSCRITOS & $\mathbf{1 8 4 9}$ \\
\hline
\end{tabular}

Fonte: MOREIRA, 1932, p. 274. (Quadro elaborado pelo autor)

O redator do volume em português foi o Rev. Galdino Moreira, com a edição do Conselho Evangélico de Educação Religiosa do Brasil, sendo o organizador e compilador de todo o material resultante do congresso o Rev. Dr. William C. Poole, da $1^{\mathrm{a}}$. Igreja Metodista de Buenos Aires e ex-presidente da Associação Mundial de Escolas Dominicais. 9

O presidente da Comissão Local da Convenção ou da Junta Executiva da Convenção no Rio de Janeiro foi o Sr. José Luiz Fernandes Braga Jr., importante industrial do Rio de Janeiro, fabricante de chapéus. Juntamente com ele, lideranças protestantes oriundas das diferentes igrejas e denominações tomaram parte na organização do evento. ${ }^{10} \mathrm{O}$ relatório prestado descreveu o grande esforço despendido, os recursos financeiros, os contatos políticos, a divulgação e a publicidade realizadas pela comissão.

Além das principais igrejas e denominações representadas, estavam presentes no congresso diversos movimentos para-eclesiásticos que compunham o campo protestante como comitês, associações, organizações e instituições em geral (MOREIRA, 1932, p. 292-305). Este quadro demonstra que o universo protestante se articulava por meio de organizações comuns fora do âmbito das denominações

\footnotetext{
${ }^{9}$ Galdino era presbiteriano e Presidente do Conselho de Educação Religiosa do Brasil.

${ }^{10}$ Um dos líderes brasileiros de grande expressão foi o Prof. Erasmo Braga, presbiteriano, falecido em 11 de maio de 1932, dois meses antes da realização da convenção no Brasil.
} 
instituídas, determinado pela mentalidade mais ecumênica. Isto não significava a ausência de tensões e de sectarismos, que reproduziam o espírito denominacionalista e fundamentalista, o qual se tornaria hegemônico no universo evangélico nas décadas seguintes até aos nossos dias.

O conteúdo do relatório traz uma visão ampla do movimento protestante mundial e brasileiro no início da década de 1930. Encontramos os discursos teológicos e as concepções políticas e pedagógicas acerca da educação e do ensino voltados, sobretudo, para a infância. Os dados e as estatísticas das escolas dominicais serviam como referência para a avaliação da presença protestante no mundo, sendo o ensino um fator de unidade num campo religioso marcadamente fragmentado e dividido. A educação era a missão comum dos diferentes ramos protestantes.

Daí compreendermos o tema do congresso "O Cristo Vivo", denotando ser o Cristo indivisível, atuante na história e na civilização, num intencional contraponto às ameaças à desintegração da civilização cristã trazidas pelo secularismo crescente, pela expectativa da guerra, pelo comunismo bolchevista e pela própria fragmentação eclesiástica. ${ }^{11}$ Outrora ativos e participantes do ideal civilizacional europeu, os protestantes já faziam aqui um deslocamento de sua presença neste processo e um questionamento dos rumos que a civilização assumia: "O Cristo vivo. Somente Ele pode salvar esta civilização do desastre, Ele é o remédio” (MOREIRA, 1932, p. 89).

Percebemos nos relatórios oficiais o tom de crítica ao processo civilizador europeu. ${ }^{12}$ A educação ainda era o instrumento de resistência ao desmoronamento moral, político e econômico. Os números e os dados analisados serviam como provas contundentes do avanço protestante no mundo e a segurança de que novos

\footnotetext{
11 “O bolchevismo é uma fé forte e lutadora, com um programa mundial que, até esta data, já obteve vitórias colossais: e não podemos conquistá-lo por meio da denúncia ou do ridículo. O bolchevismo é o maior desafio que temos na atualidade. (...) O comunismo tanto na Rússia como fora dela está tratando de inculcar essas ideias na mente da juventude. Seu credo é conciso, seu programa definido e eles propagam suas ideias com grande regozijo" (MOREIRA, 1932, p. 91).

${ }^{12} \mathrm{O}$ conteúdo do relatório contém seis partes: 1 . Introdução e abertura da convenção; 2 . Temas e tópicos gerais; 3 . Mensagens devocionais; 4. Conferências populares; 5 . Relatórios e informações; e 6. Resoluções e organização da Associação Mundial.
} 
cidadãos estavam sendo formados com perspectivas morais e religiosas diferentes. Um significativo repertório de temas foi contemplado pelos palestrantes, discursos que sintetizam a visão de mundo predominante dos protestantes, tais como a educação, o secularismo, a juventude, as raças (indígenas, negros e latinoamericanos), a guerra, a ética e as ideologias.

Estes temas eram tratados como conteúdos problemáticos que integravam o esforço da educação religiosa das igrejas, das escolas dominicais e das instituições de ensino. Havia uma crença comum estabelecida de que o futuro da humanidade dependia da educação religiosa por meio das escolas dominicais e da transmissão de valores cristãos pelas instituições de ensino cristãs e públicas.

\section{A Crítica à Civilização Secularizada}

Uma das vozes mais lúcidas do evento foi a do missionário escocês e presbiteriano John Alexander Mackay (1889-1983), importante liderança ecumênica e latino-americana no Peru e no México, que mais tarde tornou-se professor na Universidade de Princeton/EUA. ${ }^{33}$ Mackay integrava, segundo Deiros (1992, p. 751), uma geração no continente latino-americano que desenvolvia uma incipiente reflexão teológica voltada para a problemática social e missionária. Integrou o CCLA - Comitê de Cooperação na América Latina organizado em 1916 no Congresso do Panamá que impulsionou outra postura missionária protestante no continente e no Brasil. ${ }^{4}$

Ele fez palestras sobre "A resposta cristã ao secularismo", "O novo reino” e "Problemas do pensamento e da vida contemporânea". Sua leitura do secularismo é crítica por se tratar de um fenômeno então recente que eliminava o "transcendente na vida e na imaginação", afirmava a autonomia completa do homem e, "na vida

\footnotetext{
${ }^{13}$ Mackay havia tido influência do pensamento do filósofo cristão dinamarquês Kierkegaard, do espanhol Miguel de Unamuno, de Nietszche, do escritor russo Dostoievski e do teólogo alemão Karl Barth (CANTERO, 2005). Ver também Mackay (2016).

14 "Mackay articulou uma missiologia ecumênica para a América Latina no Congressos Missionários da América Latina de 1916, 1925 e 1929 e ao mesmo tempo participou do Conselho Missionário Internacional e das Conferências Mundiais de Missão" (GONZÁLEZ, 2005, p. 442).
} 
social, a tendência é para se considerarem certas instituições e esferas da vida sem outra significação ou fim, além daquilo que materialmente encerram” (MOREIRA, 1932, p. 130,131). Uma destas esferas seria o próprio Estado, sujeito aos perigos resultantes dessa secularização.

Mackay apontou as contradições do processo de secularização. Uma delas seria a própria Igreja como instituição paradoxalmente passiva e agente desse secularismo, produtor de um delírio que causava a desilusão humana pela conquista de sua própria autonomia. Em outras palavras, sua percepção era a de que os processos incidiam sobre si mesmos causando suas próprias contradições. O Estado, sendo fascista ou comunista, 15 a Cultura expressa na educação moderna e a Religião, representada pela igreja e pelo humanismo científico positivista tornaram-se esferas absolutas e substitutas da divindade. ${ }^{16}$ Por sua vez, percebeu o quanto as instituições religiosas eram portadoras, elas mesmas, de ingredientes secularizantes e haviam contribuído de forma decisiva para o declínio da civilização e para o avanço da secularização.

Mackay percebeu a autonomização das esferas sociais do Estado, da cultura e da ciência. Com argúcia, identificou o alinhamento das missões protestantes ao capitalismo que gerava "muito dinheiro e pobreza" ao mesmo tempo. O desmoronamento dos valores pelo secularismo e pela ordem social e econômica eram fenômenos da civilização em declínio. O cristianismo, de acordo com Mackay,

precisa descobrir a si mesmo, voltar à sua paixão original que implica em tomar uma deliberação inabalável de não participar em cousa alguma que porventura venha a trazer sofrimento a quem quer que seja. (...) deve haver um esforço gigantesco por parte de todos os cristãos em estimular a verdadeira justiça social. Precisamos ser realistas e reconhecer que a mera distribuição da riqueza não resolverá o problema. Não há remédio para a situação a não ser que cada qual sinta a sua alta vocação (MOREIRA, 1932, p. 197).

\footnotetext{
15 “O Fascismo, por exemplo, se converteu num absolutismo religioso, isto é, numa religião". [...]. "Sua força e poder [do comunismo] radicam-se antes numa grande ideia metafísica, isto é, que no progresso evolutivo da raça soou a hora em que o próprio universo favorece a supremacia do proletariado. [...]. Desta metafísica origina-se a tremenda paixão. Assim o comunismo já se transforma numa religião" (MOREIRA, 1932, p. 190).

16 "O segundo substituto de Deus, no mundo contemporâneo, é a cultura"; "A educação contemporânea também se converteu num absolutismo" (MOREIRA, 1932, p. 190,191).
} 
Além de Mackay, outras vozes importantes foram ouvidas. Nelas, poucas foram as mulheres que discursaram na convenção. Uma delas, a Missionária norteamericana de Saint Louis, Missouri, Hazel A. Lewis, discorreu sobre "a educação cristã das crianças", apresentando um relatório das conferências sobre o tema. Sua fala nivelou os problemas enfrentados na educação infantil em diferentes partes do mundo, sendo os desafios e as dificuldades comuns enfrentadas por parte dos educadores. Esse discurso tentava harmonizar os conflitos e as inevitáveis diferenças entre os contextos educacionais, homogeneizar as estratégias e os métodos aplicados, mesmo que com currículos e em contextos diferentes.

Um conjunto de temas foi tratado pontualmente dentro da preocupação maior com a educação. O feminismo deveria ser integrado aos ideais de paz e concórdia como combate à ameaça de guerra que rondava o mundo (MOREIRA, 1932, 236). Os indígenas eram colocados na condição de raça ou povo, portadores de particularidades culturais e históricas que deveriam ser observadas, bem como se procurar formar lideranças nativas (MOREIRA, 1932, p. 242). No relatório "entre os homens de cor da América do Norte", Horácio S. Hill, de Nova York, traduziu a situação de 20 milhões de negros ainda carentes de educação e de religião, embora educadores negros atuassem no conjunto das igrejas de negros. ${ }^{17}$

O tom pessimista e crítico, no entanto, era antagônico aos discursos outrora otimistas pela marcha da civilização, anteriores à crise do liberalismo. Hill apontou para a responsabilidade do próprio cristianismo pelo atual estado da conjuntura mundial e identificou os eixos da modernidade que assolavam o mundo civilizado, assim como os negros norte-americanos: o racionalismo, a ciência, a tecnologia e a religião. Este conjunto havia proporcionado ao mundo a guerra, o capitalismo, o racismo e a depressão econômica.

\footnotetext{
17 “É interessante observar que seis das maiores igrejas de negros em Nova York, cujo número de membros comungantes vai de 2000 a 10060, estão reajustando seus programas escolares, de sorte que no fim de 1932 se principiará a execução de um plano quinquenal de educação cristã, sob a direção de competentes especialistas, que farão marchar lado a lado a religião e a educação" (MOREIRA, 1932, p. 243).
} 
Tivemos sucesso em introduzir na vida o platonismo mórbido, o materialismo e o mecanismo; mas, tudo isto está indo por água abaixo. Tivemos sucesso em introduzir em nossas vidas uma religião acerca de Jesus; mas, desta "religião" os resultados foram estes: a guerra, a luta com o capitalismo, os atritos de raça em vários países. A diversas causas se procura atribuir essa depressão sem paralelo que atingiu o mundo nestes três últimos anos. Reformadores e profetas da paz perderam-se num verdadeiro labirinto, esperando em vão que se aceite a Liga das Nações ou se faça um tratado, que venha pôr fim à guerra. Os que estudam os conflitos de raça procuram uma solução definitiva para este grave problema. As classes laboriosas procuram uma base justa para distribuição de riquezas, enquanto os interessados nas reformas políticas se iludem com uma fórmula utópica, que façam com que para todos os homens, sem distinção de raça, credo ou cor, se inaugure uma fase de paz, prosperidade e felicidade (MOREIRA, 1932, p. 248).

Para os males da civilização, o remédio era a transmissão ao indivíduo pela educação de uma religião viva centrada em Jesus Cristo e na adoção de uma ética voltada para a prática da temperança. Embora esse protestantismo fizesse, nesse momento, a crítica a si mesmo e aos rumos da sociedade ocidental, a solução apontada recaía nos métodos educacionais objetivamente aplicados. Eles deveriam ser direcionados à transformação do indivíduo, à formação de valores permanentes em seu caráter, cuja finalidade era a de assegurar uma moral pessoal e coletiva, desde a vida privada extensiva ao público.

\section{Os Protestantes e o Governo Provisório de Vargas}

Mas este programa enfrentaria seus próprios obstáculos no modo como o Estado passou a se portar e o governo a se conduzir diante do conjunto da sociedade. Na América Latina e no Brasil, iniciava-se o período dos governos ditatoriais com nuances fascistas e populistas, numa nova conjugação de forças sociais e políticas onde a Igreja Católica retornava como interlocutora e definidora de políticas públicas.

Os protestantes no Brasil celebraram o advento da República laica e a separação entre Estado e Igreja em 1889. Conseguiram ampliar sua presença no território nacional através de templos, escolas, hospitais e outras instituições. Sobretudo em relação à educação, "a crença generalizada entre os missionários 
protestantes atuantes no Brasil, na primeira metade do século XX, é que o ensino formal seria um fator de transformação social ...” (ALMEIDA, 2015, p. 68).

Em 1930, segundo Braga e Grubb, eram 1358 igrejas (templos) com 135.390 membros comungantes, na proporção de 1 protestante para cada 310 brasileiros, numa população total de 41.477.824 (BRAGA \& GRUBB, 1932, p. 106). As escolas dominicais contavam com 121.335 alunos contabilizados, indicando um contingente de futuros praticantes pela via do ensino doutrinário (BRAGA \& GRUBB, 1932, p. 141). Os evangélicos comungantes por denominação estavam assim distribuídos, permitindo-nos identificar as principais denominações eclesiásticas daquele momento.

\section{Quadro 3 - Evangélicos brasileiros por Denominação}

\begin{tabular}{|c|c|}
\hline Denominações Eclesiásticas & $100 \%$ \\
\hline Batistas & $30 \%$ \\
\hline Presbiterianos & $24 \%$ \\
\hline Metodistas & $11 \%$ \\
\hline Presbiterianos Independentes & $10 \%$ \\
\hline Pentecostais & $9,5 \%$ \\
\hline Adventistas & $5 \%$ \\
\hline Congregacionalistas & $3 \%$ \\
\hline Episcopais & $2,5 \%$ \\
\hline Outros & $4,5 \%$ \\
\hline
\end{tabular}

Fonte: BRAGA \& GRUBB, 1932, p. 71.

Presbiterianos e Batistas representavam 64\% dos evangélicos brasileiros, seguidos dos metodistas e dos pentecostais. Estes eram ainda minoritários principalmente por meio das Assembleias de Deus e da Congregação Cristã do Brasil, com cerca de 20 anos de inserção religiosa apenas. Desde a primeira década do século XX, os Batistas apresentaram maiores taxas de crescimento (BRAGA \& GRUBB, 1932, p. 68). 
Contudo, os dados não registraram os luteranos afixados na região sul do país, considerados à parte por conta da imigração germânica, que começara havia pouco mais de um século. Estes luteranos contavam com cerca de 60.401 membros, numa comunidade cristã mais ampla de 215.740, e que reunia quatro sínodos: o Sínodo Evangélico do Rio Grande do Sul, o Sínodo Evangélico do Brasil Central, o Sínodo Luterano e o Sínodo Evangélico de Santa Catarina, Paraná e outros estados. Apesar de não serem inseridos inicialmente, a pesquisa os identificou em outra categoria (das "Igrejas Evangélicas Germânicas"), junto com os luteranos do Sínodo do Missouri e de outros grupos imigrantes com suas igrejas como os batistas, os adventistas e as igrejas independentes (BRAGA \& GRUBB, 1932, p. $51,52) \cdot{ }^{18}$

Nas primeiras décadas do século $\mathrm{XX}$, a relação dos protestantes com o Estado foi de distanciamento, com pouca representação política de seus interesses, inserção em partidos políticos e em movimentos sociais. Foi na esfera da sociedade civil que os protestantes construíram suas ações. Esta postura mudaria a partir do governo varguista e o evento da convenção demarcou tais mudanças. Mais organizados e coesos, sobretudo em torno do movimento de cooperação e da criação da Confederação Evangélica do Brasil em 1934, as ações no campo político incidiram com maior representatividade.

Diante das ambições católicas e das novas possibilidades eleitorais, líderes evangélicos (principalmente presbiterianos) que estão articulando uma Confederação Evangélica, lançam um Memorial, em maio de 1932. Recomenda que os "evangélicos cerrem fileiras ... Urge que a voz dos evangélicos ... se faça ouvir por aquelas que vierem a compor a Assembleia Constituinte" (FRESTON, 1994, p. 21).

As relações com o governo provisório de Vargas foram, na perspectiva dos organizadores, amistosa e de apoio à realização do evento. Após o evento, os oficiais executivos da convenção estiveram com Getúlio Vargas no Palácio do

\footnotetext{
${ }^{18}$ Parece-nos que a condição étnica levou a esta identificação separada dos demais grupos eclesiásticos oriundos da Europa e dos Estados Unidos.
}

Horizonte, Belo Horizonte, v. 15, n. 47, p. 949-973, jul./set. 2017 - ISSN 2175-5841 
Catete, no Rio de Janeiro, agradecendo o apoio recebido e demonstrando a força das igrejas protestantes no país. ${ }^{19}$

\section{Foto 1 - Executivos com Getúlio Vargas}

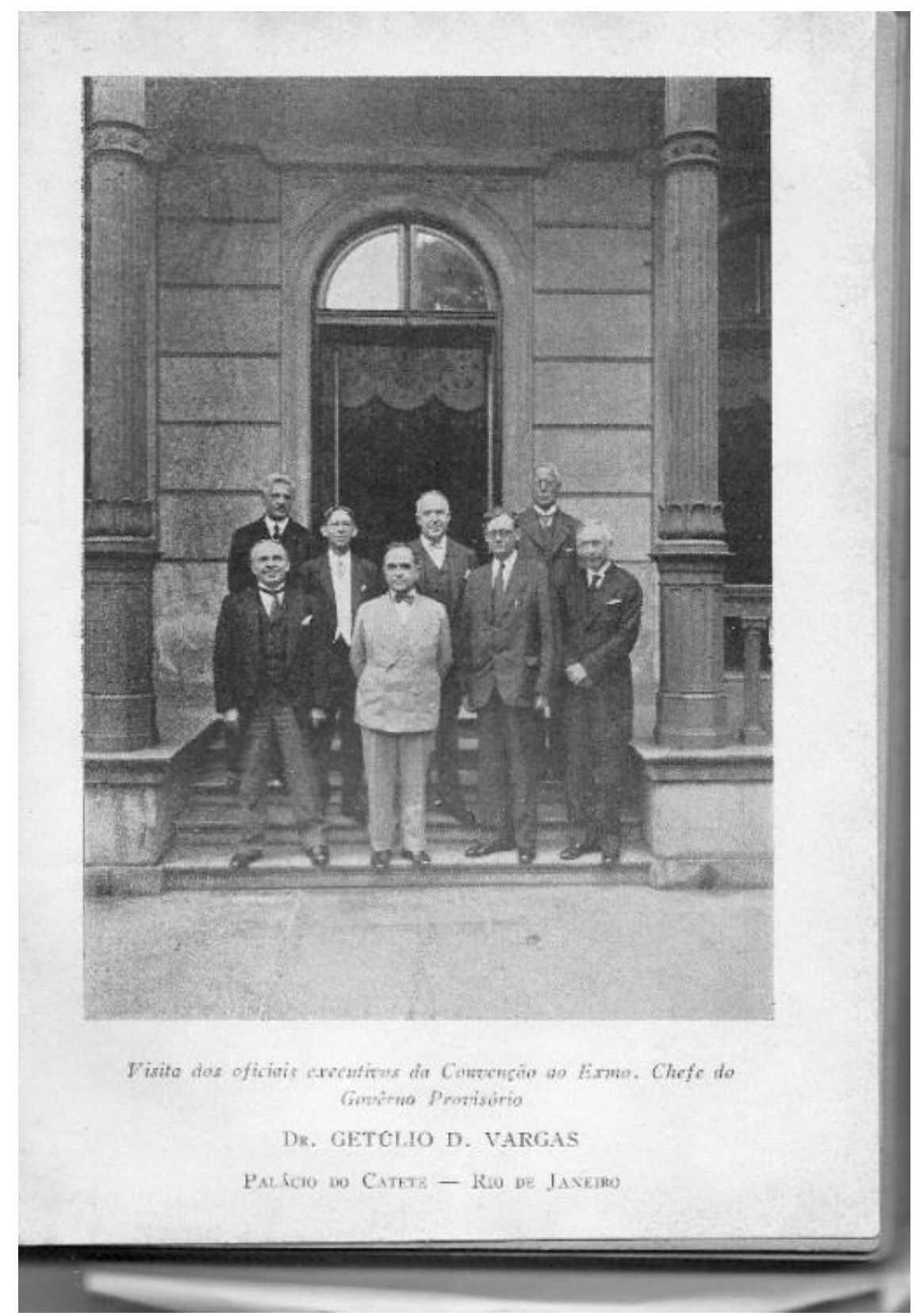

Fonte: MOREIRA, 1932, p. 192.

\footnotetext{
${ }^{19}$ A reportagem da "visita ao Chefe Provisório" foi registrada na edição do Jornal do Brasil, Quarta-feira, 3 de agosto de 1932, N. 183,
} Ano XLII, p. 10. (JORNAL DO BRASIL, 1932). 


\title{
O governo contribuiu para o evento com uma série de benefícios:
}

\begin{abstract}
Abatimento nas passagens do Lloyd Brasileiro e [da] E. de Ferro Central do Brasil para os delegados, facilidade dos "vistos" consulares e, até em alguns casos especiais, facilidades e cortesias quanto à bagagem dos delegados; entrada gratuita e franca dos objetivos destinados à Exposição; o uso gratuito de vários edifícios públicos, o Teatro Municipal, o Teatro João Caetano, a Escola de Belas Artes, e a representação do Chefe do Governo Provisório à sessão inaugural. O Dr. Getúlio Vargas, por várias vezes, recebeu comissões da Junta, sempre demonstrando vivo interesse na marcha dos trabalhos dela e desta Convenção (MOREIRA, 1932, p. $28,29)$.
\end{abstract}

Nas boas vindas do governo brasileiro na abertura da convenção, o então interventor no Distrito Federal, Pedro Ernesto, assim se dirigiu aos congressistas:

1. Em nome da cidade do Rio de Janeiro, Capital da República dos Estados Unidos do Brasil, eu apresento as saudações de boas-vindas aos dignos delegados nacionais e estrangeiros, representando cerca de 50 países da terra, aqui presentes na $11^{\mathrm{a}}$. Convenção Mundial de Escolas Dominicais.

2. Nosso grande desejo é que a fé inspiradora de vossos ideais seja para o Brasil um incitamento, que contribua para aprimorar na alma de seus filhos excelsas virtudes, um são patriotismo e uma nítida compreensão de seus sagrados deveres para com Deus e os Homens.

3. A tradicional porta da hospitalidade brasileira abre-se, de par em par, para vos acolher prazerosamente.

4. Queremos que não somente se grave em vossas retinas a magnificência da natureza com que nos dotou o Criador, mas que também sintais no coração os anseios de um povo que aspira elevar-se para ser útil à humanidade.

5. E sobre os vossos esforços em prol da pureza da alma, da saúde do corpo e da elevação espiritual da juventude, há de pairar a gratidão imorredoura das futuras gerações.

6. É nesta esperança e confiança que saudamos cordialmente os delegados da Convenção de Escolas Dominicais.

Pedro Ernesto. Interventor no Distrito Federal (MOREIRA, 1932, p. $32,33)$.

Estas relações amistosas e de apoio entre os protestantes e o governo brasileiro conflitavam com a postura do governo na política para a educação 
pública e nas suas ligações com a Igreja Católica (SERBIN, 2008, p. 100). ${ }^{20}$ Internamente, o Brasil retomava a discussão em torno da educação como pauta da iminente assembleia constituinte. Vargas exercia a chefia do governo provisório após o golpe de estado imposto em 1930, enfrentando "agitações e crises sucessivas nos meios civis e militares" (PANDOLFI, 2012, p.23). A instabilidade política resultante da demora da nova carta constitucional, da insatisfação das oligarquias de São Paulo depostas do poder e de outras formas de pressão, levou à eclosão de uma guerra civil (PANDOLFI, 2012, p.25).

O debate na constituinte tinha a Igreja Católica numa posição de maior poder e influência junto ao governo federal, no tocante ao ensino religioso nas escolas públicas (SERBIN, 2008, p. 100). Os protestantes reivindicavam a neutralidade do estado laico, defendiam posições favoráveis ao divórcio absoluto, o parlamentarismo, o pacifismo e lutavam pela participação evangélica na discussão de um projeto de educação pública laica (FRESTON, 1994, p. 21). Os liberais defendiam a não ingerência da religião na educação pública promovida pelo estado ou a distribuição de espaços iguais às religiões.

Ampliava-se, então, a intervenção do Estado na área do ensino público. O ensino religioso nas escolas públicas se tornaria, até os nossos dias, uma esfera de disputas entre as religiões institucionalizadas na defesa da confessionalidade deste ensino. Interessava aos protestantes brasileiros, nesse momento, expor suas propostas para a nação, mostrar seus programas sociais executados pela educação (alfabetização e escolas) e medir forças ante as pretensões da Igreja Católica. ${ }^{21}$

\footnotetext{
${ }^{20}$ Segundo José Oscar Beozzo, “antes mesmo de desencadeada a Revolução de 30, a mudança de registro já é notável e se a Igreja vai lutar pela mudança de seu estatuto jurídico na sociedade brasileira, o fará em grande parte no sentido de prestar seu concurso espiritual e ideológico ao fortalecimento do Estado e do bloco das classes dominantes, face à ascensão das classes subalternas" (BEOZZO, 1995, p. 291). Para Riolando Azzi, "se por um lado o governo reconhecia a importância da parceria da Igreja com apoio ao poder político, por outro continuava vigilante para impedir que ela pudesse tornar-se um aliado prepotente, enfraquecendo ou dificultando o próprio caráter decisório do Estado" (AZZI \& GRIJP, 2008, p. 224).

21 "Aproveitando o período de instabilidade política durante os primeiros meses do governo revolucionário, a hierarquia católica decidiu reivindicar com urgência uma mudança na legislação federal, permitindo o ensino religioso nas escolas públicas, como já fora concedido em 1928 para o Estado de Minas Gerais" (AZZI \& GRIJP, 2008, p.223).
} 
As escolas paroquiais evangélicas lutavam pela sobrevivência e espaço nessa nova conjuntura que se formava.

\begin{abstract}
Devido ao crescente controle que o Governo exerce em toda a instrução no Brasil e em toda a parte, as escolas cristãs lutam sempre com grandes dificuldades. As escolas estaduais e nacionais tomam o lugar das escolas paroquiais e, assim, a educação religiosa nas escolas missionárias está sendo ameaçada. À vista disso, a responsabilidade da educação cristã pesa cada vez mais sobre a igreja. A igreja local e os concílios nacionais da igreja deveriam considerar essa questão e resolver como conseguir a educação cristã de seus filhos em circunstâncias que estão sempre mudando (MOREIRA, 1932, p. 234).
\end{abstract}

Observa-se nesta fala o processo de avanço do Estado intervindo em áreas que pertenciam à religião e o deslocamento da prática educativa à esfera restrita das igrejas locais. O desafio, então, estava na preparação de lideranças religiosas (pastores) e de professores capazes de prover às crianças evangélicas uma educação cristã que fosse além de uma instrução religiosa. Esta tarefa se daria tanto nas escolas paroquiais missionárias, nas escolas dominicais das igrejas locais como nas “instituições educativas do governo”. Sentia-se a perda de espaço e influência das escolas evangélicas nesse novo cenário.

A estratégia dos protestantes implicava na possibilidade de "estabelecer pensões evangélicas em conexão com as instituições do governo” e na investigação da "possibilidade de um registro permanente de alguns departamentos de preparação de professores em conexão com as escolas missionárias” (MOREIRA, 1932, p. 235). Tais estratégias se direcionavam à garantia de espaço nesse novo ordenamento da política pública para o ensino. Ante a possível "eliminação do ensino religioso, as missões não deveriam aceitá-lo” (MOREIRA, 1932, p. 235).

O debate sobre o ensino religioso nas escolas públicas seria acirrado na discussão da nova carta constitucional promulgada em 1934. O deputado paulista pertencente à Igreja Metodista do Brasil, Guaracy Silveira, ligado ao PSB (Partido Socialista Brasileiro) representou no plenário a visão e os interesses dos evangélicos nesta questão (ALMEIDA \& FERRAZ, 2014, p. 37-73). O deputado 
defendeu temas como o voto feminino, a regulamentação do divórcio, o controle do Estado sobre lucros abusivos, a igualdade de salários para trabalhadores de ambos os sexos e o ensino de Moral e Cívica nas Escolas Públicas, ao invés do ensino religioso. Mas, sua atuação não contou com o apoio claro das igrejas e das denominações distanciadas das lutas e das demandas dos partidos e dos sindicatos, embora representasse certas aspirações dos evangélicos (OLIVEIRA, 2007, p. 5).

Pontuava-se, assim, a presença protestante no espaço público da política oficial, mas a agenda das igrejas não incluía uma agenda de participação e debates junto aos movimentos sociais. Havia a intervenção maior do Estado nas esferas sociais em aliança com os católicos, mas, ao mesmo tempo, era o promotor da laicização da sociedade ao conduzir este processo e demarcar os lugares e os limites das instituições religiosas. Ambiguamente, “o governo Vargas (...) dispunha a favorecer os interesses da instituição eclesiástica, impedindo-a, porém, de possuir direitos adquiridos na esfera do próprio Estado” (AZZI \& GRIJP, 2008, p. 224).

Silveira foi presença protestante isolada neste cenário inicial da década de 1930. Como diz Paul Freston:

\begin{abstract}
Em termos constitucionais, sua presença provavelmente fortaleceu o elemento anticlerical, que conseguiu, senão derrubar, pelo menos atenuar as reivindicações católicas. Marcou a estreia efetiva dos protestantes na política nacional, possibilitada pela nova legislação eleitoral e impulsionada pelas pretensões católicas. Para estes, o reforço protestante rendeu uma cadeira a mais, mas posteriormente o aliado protestante deixou de corresponder expectativas. A especificidade religiosa de sua participação fora subestimada pelos que a solicitaram, não pela última vez na história política protestante (FRESTON, 1994, p. 23).
\end{abstract}

Contudo, a realização da convenção no Rio de Janeiro confluiu para certas tomadas de posições dos protestantes no cenário interno, sob fortes tensões e instabilidades políticas. Uma delas foi a criação da Confederação Evangélica no Brasil (CEB) no ano de 1934, o mesmo da promulgação da constituição de cunho liberal. A CEB marcou um novo capítulo da presença protestante no espaço público até o golpe de 1964, quando foi alvo de intervençãoe se enfraqueceu perdendo 
espaço no campo evangélico brasileiro, até encerrar suas atividades em 1980 (BARRETO JR., 2011, p. 311; tb. ROSA, 2015, p. 133). A CEB representou na sociedade e junto ao Estado a pluralidade interna dos evangélicos, publicou jornais, revistas, hinários e materiais pedagógicos para as igrejas. Reproduziu o pensamento ecumênico no contexto brasileiro nutrido pelo Evangelho Social e agregou a diversidade teológica, denominacional e política dos protestantes, não sem conflitos e tensões.

\section{Considerações Finais}

A análise do documento e do relatório atesta as mudanças discursivas dos protestantes como o fim do otimismo pelo futuro da civilização no ocidente, a partir das evidências de seu declínio e do período entre guerras. Por outro lado, construía-se uma autocrítica na participação e contribuição do cristianismo com aquele quadro, vendo ainda na educação um instrumento de resistência e afirmação de ideais religiosos.

Algumas falas dos congressistas discerniam o protestantismo enquanto força religiosa e cultural como produto de mudanças sociais e, ao mesmo tempo, como agente responsável por elas. Esta autocrítica, no entanto, não atingia de todo ainda as relações estruturais que havia entre seus discursos, práticas e instituições com o sistema capitalista travestido sob o manto discursivo da civilização.

Eram a tentativa de reintroduzir a religião enquanto força de sentido no espaço público (político e cultural) e no campo religioso. Embora percebendo e suspeitando dos seus projetos e modelos, tinha a convicção de que ainda era um fator que contribuía diretamente nos rumos da sociedade de sua época.

No contexto brasileiro, os protestantes sentiram a necessidade de novas formas de atuação no espaço público, sobretudo por meio da educação, diante da aproximação do governo de Vargas com os católicos e das condições colocadas pela 
nova carta constitucional em discussão. Novos canais de diálogo deveriam ser abertos em disputas por maior representatividade na sociedade.

No entanto, no cenário oficial da política, os protestantes optaram pelo distanciamento e por uma representatividade institucional com a fundação em 1934 da CEB. Embora promotores de práticas educacionais, mantiveram-se distantes do engajamento em movimentos sociais, partidos políticos e sindicatos, postura que mudaria a partir do fim de década de 1950 e no contexto do golpe militar em 1964.

O período de 1930 a 1964 permanece como temporalidade a ser mais explorada pelos historiadores do protestantismo no Brasil. Pois, nela, foram configuradas outras formas de representações do religioso no espaço público.

\section{REFERÊNCIAS}

ALMEIDA, Vasni. Religião e educação: práticas de converter e de ensinar dos Metodistas no Brasil. Curitiba: Editora Prismas, 2015.

ALMEIDA, Vasni; FERRAZ, Cilas. Guaracy Silveira: um protestante na política. Rio de Janeiro: Novos Diálogos, 2014.

ANDRADE, Maristela Oliveira de. A Religiosidade Brasileira: o pluralismo religioso, a diversidade de crenças e o processo sincrético. In: CAOS - Revista Eletrônica de Ciências Sociais, Paraíba, n. 14, p. 106-118, set. 2009.

AZZI, Riolando; GRIJP, Klaus van der. História da Igreja no Brasil: ensaio de interpretação a partir do povo. Tomo II/3-2: terceira época: 1930-1964. Petrópolis, RJ: Vozes, 2008.

BARRETO JR., Raimundo C. "O movimento ecumênico e o surgimento do Setor de Responsabilidade Social no Protestantismo Brasileiro”. In: Numem: Revista de Estudos e Pesquisa da Religião, Juiz de Fora, v. 13, n. 1 e 2, p. 273-323, 2011. Disponível em: <https://numen.ufff.emnuvens.com.br/numen/article/viewFile/1503/1050>. Acesso em: 29 ago. 2017.

BEOZZO, José Oscar. A Igreja entre a Revolução de 30, o Estado Novo e a Redemocratização. In: PIERUCCI, Antonio Flavio de Oliveira [et al]. O Brasil republicano: economia e cultura (1930-1964). 3 ed. Rio de Janeiro: Bertrand Brasil, 1995. 
BIRMAN, Patrícia, org. Religião e espaço público. São Paulo: Attar Editorial, 2003.

BOURDIEU, Pierre. A economia das trocas simbólicas. 5 ed. São Paulo: Perspectiva, 2009.

BRAGA, Erasmo; GRUBB, Kenneth G. The Republic of Brazil: a survey of the religious situation. London, New York, Toronto: World Dominion Press, 1932.

CANTERO, Luis Eduardo. El pensamiento teológico de John Mackay. Un aporte a la teología latinoamericana, en especial Colombia. Teología y cultura, Colombia, año 2, vol. 4, p. 1-7, dic, 2005. Disponível em:

<http://www.teologos.com.ar/arch_rev/cantero_mackay.PDF>. Acesso em: 29 jul. 2017.

DEIROS, Pablo Alberto. Historia Del cristianismo em América Latina. Buenos Aires: Fraternidad Teológica Latinoamericana, 1992.

FARIS, John T., ed. The Sunday School and The Healing of the nations: The Official Book of the Wolrd's Ninth Sunday School Convention, held in Glasgow, Scotland, July 18-26, 1924. New York City, USA: Wolrd”s Sunday School Association, 1924.

FARIS, John T., ed. "The Kingdom Come": The Official Book of the Wolrd's Tenth Sunday School Convention, held in Los Angeles, California, July 11-18, 1928. New York City, USA: Wolrd"s Sunday School Association, 1928.

FRESTON, Paul. Evangélicos na Política Brasileira: história ambígua e desafio ético. Curitiba: Encontrão, 1994.

GIUMBELLI, Emerson. A presença do religioso no espaço público: modalidades no Brasil. In: Religião \& Sociedade, Rio de Janeiro, v. 28, n. 2, p. 1-12, 2008.

GONZALEZ, Justo L., ed. Dicionário ilustrado dos intérpretes da fé. Trad. Reginaldo Gomes de Araújo. Santo André, SP: Editora Academia Cristã Ltda, 2005.

HERVIEU-LÉGER, Daniele. O peregrino e o convertido: a religião em movimento. Trad. João Batista Kreuch. Petrópolis, RJ: Vozes, 2008.

HERVIEU-LÉGER, Daniele; WILLAIME, Jeasn-Paul. Sociologia e religião: abordagens clássicas. Trad. Ivo Storniolo. Aparecida, SP: Idéias \& Letras, 2009.

MACKAY, John Alexander. Jon Alexander Mackay (1989-1983). Disponível em: <http://www.teologos.com.ar/arch/mackay.PDF>. Acesso em: 29 jul. 2017.

MONTERO, Paula. Secularização e espaço público: a reinvenção do pluralismo religioso no Brasil. Etnográfica, Portugal, v. 13, n. 1, pp. 7-16, maio 2009.

MOREIRA, Galdino, ed. “O Cristo Vivo”: Relatório Oficial da $11^{\text {a }}$ Convenção Mundial de Escolas Doinicais, Rio de Janeiro, 25 a 31 de julho de 1932. Rio de Janeiro: Conselho Evangélico de Educação Religiosa do Brasil, 1932. 
OLIVEIRA, Cilas Ferraz de. Protestante na política: o caso de Guaracy Silveira. X Simpósio Internacional Processo Civilizador. Campinas, SP: 2007. Disponível em <http://www.uel.br/grupoestudo/processoscivilizadores/portugues/sitesanais/anais1o/Ar tigos_PDF/Cilas_Ferraz.pdf>. Acesso em: 10 abr. 2010.

PANDOLFI, Dulce Chaves. Os anos 1930: as incertezas do regime. In: FERREIRA, Jorge; DELGADO, Lucilia de Almeida Neves. O tempo do nacional-estatismo: do início da década de 1930 ao apogeu do Estado Novo. 5 ed. Rio de Janeiro: Civilização Brasileira, 2012.

ROCHA, João Gomes da. Lembranças do Passado: Dr. Robert Reid Kalley. Rio de Janeiro: Novos Diálogos, 2013, 384 p. Volume I.

ROSA, Wanderley Pereira da. Por uma fé encarnada: teologia social e política no protestantismo brasileiro. 2015. 298f. Tese (Doutorado)- Pontifícia Universidade Católica do Rio de Janeiro, Departamento de Teologia, Rio de Janeiro, 2015.

SERBIN, Keneth P. Padres, celibato e conflito social: uma história da Igreja Católica no Brasil. Trad. Laura Teixeira Motta. São Paulo: Companhia das Letras, 2008.

SOUZA, Beatriz Muniz; MARTINO, Luis Mauro Sá, orgs. Sociologia da religião e mudança social: católicos, protestantes e novos movimentos religiosos. São Paulo: Paulus, 2004.

STEIL, Carlos Alberto. Pluralismo, modernidade e tradição: transformações do campo religioso. In: Ciências Sociais e Religião, Porto Alegre, v. 3, n. 3, p. 115-129, out. 2001.

TEIXEIRA, Faustino; MENEZES, Renata. As religiões no Brasil: continuidades e rupturas. Petrópolis, RJ: Vozes, 2006.

VISITA DO CHEFE PROVISÓRIO. Jornal do Brasil, quarta-feira, 3 ago. 1932, n. 183, Ano XLII. Biblioteca Digital da Fundação Biblioteca Nacional. Disponível em: <http://bndigital.bn.gov.br/hemeroteca-digital/>. Acesso em: 15 set. 2017. 